\title{
Produção de leguminosas em função do espaçamento no Brejo Paraibano
}

\author{
Shênia Santos Monteiro ${ }^{1}$, Shirley Santos Monteiro ${ }^{2}$, Jômane Costa de Jesus ${ }^{2}$, Dualyson da Silva Santos ${ }^{2}$, Juliana \\ Ferreira de Lima², Fillipe Silveira Marini ${ }^{2}$
${ }^{1}$ Universidade Federal de Campina Grande; shenia-monteiro@ @otmail.com; ${ }^{2}$ Universidade Federal da Paraíba; shirley_pinto_monteiro@hotmail.com; costajomane@gmail.com; dualyson@ hotmail.com; julianacavnufpb@hotmail.com; fsmarini@yahoo.com.br.

\begin{abstract}
RESUMO: O espaçamento adequado para cada cultura é essencial para expressar seu potencial genético e produtivo característico da cultura. Neste sentido, objetivou-se avaliar a produção das Fabaceae Mucuna aterrima e Dolichos lablab em diferentes espaçamentos no Brejo Paraibano. O experimento foi conduzido na área comunitária do Projeto de Assentamento Nossa Senhora de Fátima, Bananeiras-PB. Usou-se o delineamento em blocos casualizados, no esquema fatorial 2 x 3, sendo duas Fabaceae (M. aterrima e D. lablab) e três espaçamentos $(0,50$ x 0,50 m; 0,75 x 0,50 m e 1,0 x $0,50 \mathrm{~m})$, com três repetições. Avaliou-se o peso da vagem com e sem sementes, peso das sementes, número de sementes por vagem, peso de 100 sementes e a produção total. A $M$. aterrima apresentou maior desempenho produtivo. O espaçamento $0,50 \times 1,0 \mathrm{~m}$, apresentou melhor resultados no desenvolvimento e produção de sementes de $M$. aterrima no Brejo Paraibano.
\end{abstract}

PALAVRAS-CHAVE: Dolichos lablab; Mucuna aterrima; Produção agroecológica de sementes.

\section{INTRODUÇÃO}

A família botânica Fabaceae (leguminosas) se destaca pela riqueza e número de espécies deste grupo de plantas, considerado o grupo mais evoluído (SANTOS et al., 2018). O Brasil é rico em leguminosas; estimativas revelam que estas espécies se desenvolvem em diferentes ecossistemas, o que torna estas plantas propícias à produção agrícola, devido à alta concentração de nitrogênio em sua parte aérea (SOUZA, 2012).

As práticas agrícolas como adubação verde, entre outras, melhoram a qualidade do solo, garante economia com uso de adubos, protege o solo contra erosão e o aquecimento. Esta prática promove também a melhoria da estrutura do solo, permitindo mais infiltração de água (MARES GUIA et al., 2018). Dentre as plantas cultivadas com está finalidade, pode-se destacar as Fabaceae, devido à capacidade de fixação biológica do nitrogênio através da associação simbiótica com bactérias, como crotalária (Crotalaria ssp.), feijão de porco (Canavalia ensiformis), guandu (Cajanus cajan), leucena (Leucaena ssp.), lablab (Dolichos lablab) e mucuna (Mucuna ssp.) (SILVA et al., 2011).

Mucuna aterrima e Dolichos lablab apresentam bom desempenho, mesmo em condições adversas de solo e clima (SOUZA et al., 2016). Essas culturas são caracterizadas pelo rápido crescimento e capacidade de melhorar as condições físicas, químicas e biológicas do solo, uma vez que podem produzir uma quantidade considerável de biomassa e fixar $157 \mathrm{~kg}$. ha.ano $^{-1}$ (M. aterrima) e $180 \mathrm{~kg}$.ha.ano ${ }^{-1}$ (D. lablab) de nitrogênio, além de controlarem plantas invasoras e serem amplamente utilizadas em sistema de rotação de cultura e adubação verde (WUTKE et al., 2007).

Os conhecimentos do arranjo das culturas são necessários, pois constitui prática importante de manejo para a obtenção de produtividades próximas ao potencial produtivo da cultura, permitindo um maior crescimento e desenvolvimento das plantas, gerando sementes de qualidade para produção agrícola (GOMES; KARAM, 2018).

As sementes estão em constante processo de evolução e adaptação ao meio e às práticas de manejo, e esse processo sofre a influência dos tradicionais sistemas de trocas e intercâmbio de material genético, praticada por comunidades rurais (LONDRES, 2014). Estas sementes são consideradas recursos básicos e relevantes para autonomia, liberdade, segurança alimentar e nutricional, necessárias para permanência do homem no campo com a diversificação produtiva (ARAÚJO, et al., 2013).

Baseado em expectativa agroecológica faz-se necessário a valorização das sementes tradicionais que mantenha a biodiversidade local e o fortalecimento da agricultura familiar, sendo fundamental a preservação e seleção de sementes para garantir tal biodiversidade genética e soberania alimentar da localidade (SILVA; LOPES, 2016). Diante disso, objetivou-se avaliar a produção das Fabaceae M. aterrima e D. lablab em função de diferentes espaçamentos, no Brejo Paraibano.

\section{MATERIAL E MÉTODOS}

O experimento foi conduzido na área comunitária do Projeto de Assentamento Nossa Senhora de Fátima no município de Bananeiras-PB, a qual possui clima tropical chuvoso, quente e úmido, conforme Köppen. A coleta de dados, análises e armazenamento do material avaliado foi conduzido nas instalações do Laboratório de Tecnologias de Sementes do CCHSA/UFPB.

O delineamento experimental usado foi em blocos casualizados, com os tratamentos arranjados em esquema fatorial 2 × 3, com três repetições, sendo o primeiro fator constituído pelas Fabaceae Mucuna aterrima e Dolichos 
MONTEIRO, S. S. et al. Produção de leguminosas em função do espaçamento no Brejo Paraibano. In: II Congresso Paraibano de Agroecologia \& IV Exposição Tecnológica, 2019. Anais... Caderno Verde de Agroecologia e Desenvolvimento Sustentável, Pombal, v. 9, n.7, e-6926, 2019.

lablab, o segundo pelos espaçamentos $(0,50 \times 0,50 \mathrm{~m} ; 0,75 \times 0,50 \mathrm{~m} \mathrm{e} 1,0 \times 0,50 \mathrm{~m})$. As parcelas experimentais foram de $3,0 \times 4,0 \mathrm{~m}$. A área total das parcelas foi de $12 \mathrm{~m}^{2}$, sendo utilizadas como parcela útil as linhas centrais de cada parcela.

O preparo do solo consistiu da aração e gradagem sem calagem ou adubação. Para a realização do plantio foram utilizadas a sementes de $M$. aterrima e D. lablab cedida pelo Banco de Sementes do Laboratório de Análises e Tecnologia de Sementes do CCHSA/UFPB.

O experimento teve início em maio e estendeu-se até o mês de setembro de 2015. Durante este período foi realizado o preparo do solo e demarcações das parcelas. Foi também realizada a semeadura manualmente, colocando-se 3 sementes por cova com aproximadamente $5 \mathrm{~cm}$ de profundidade. Depois de uma semana da emergência, realizou-se o desbaste, deixando uma planta por cova referente aos tratamentos acima citados.

Aos 150 dias após a semeadura, realizou-se a colheita do experimento. Foram avaliadas as características: peso de vagem com semente (PVcS), peso de vagem sem sementes (PVsS), número de sementes por vagem (NSpV), peso da semente (PS), peso de 100 semente (P100) e produção total (PT). Para avaliação das variáveis foram utilizados balança analítica (RADWAG).

As análises de variância para as características avaliadas foram realizadas através do programa estatístico SAS, utilizando-se o Teste Tukey ao nível de 5\% de probabilidade para se fazer as comparações das médias.

\section{RESULTADOS E DISCUSSÃO}

Observa-se na Figura 1,2 e 3 os resultados das análises de produção das vagens e sementes de Mucuna aterrima e Dolichos lablab, as quais apresentaram diferença significativa para todas as variáveis analisadas.

Figura 1. O peso de vagem com sementes está representado por barras no eixo principal e o peso de vagem sem sementes no eixo secundário por linhas tracejadas de Mucuna aterrima e Dolichos lablab em diferentes espaçamentos. Bananeiras-PB, UFPB, 2019. Letras maiúsculas comparam as espécies de leguminosas entre si dentro de cada espaçamento. Letras minúsculas comparam os espaçamentos entre si dentro de cada leguminosa.

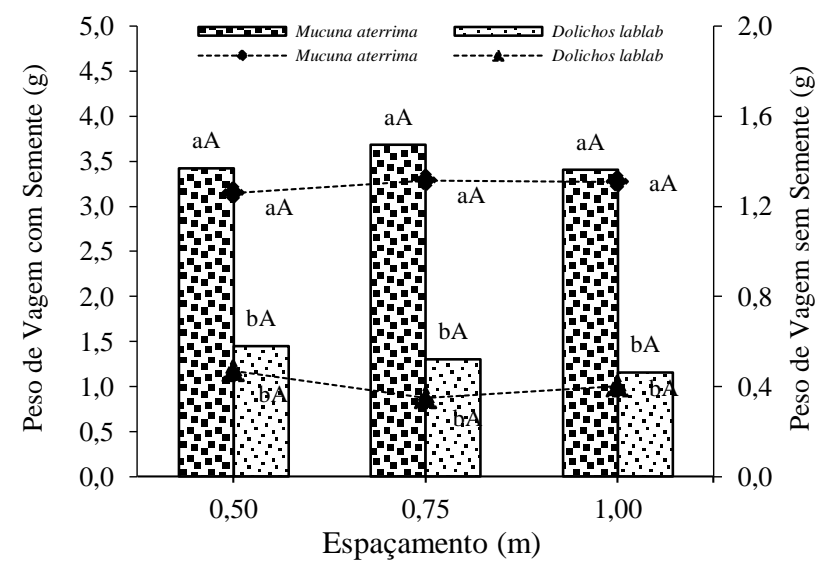

Figura 2. O número de semente por vagem está representado por barras no eixo principal e o peso da semente no eixo secundário por linhas tracejadas de Mucuna aterrima e Dolichos lablab em diferentes espaçamentos. Bananeiras-PB, UFPB, 2019. Letras maiúsculas comparam as espécies de leguminosas entre si dentro de cada espaçamento. Letras minúsculas comparam os espaçamentos entre si dentro de cada leguminosa.

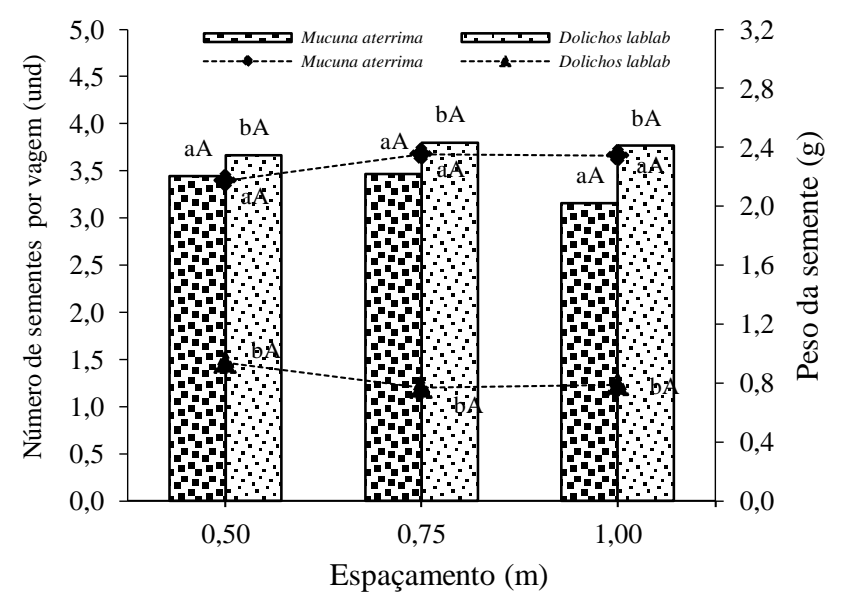


MONTEIRO, S. S. et al. Produção de leguminosas em função do espaçamento no Brejo Paraibano. In: II Congresso Paraibano de Agroecologia \& IV Exposição Tecnológica, 2019. Anais... Caderno Verde de Agroecologia e Desenvolvimento Sustentável, Pombal, v. 9, n.7, e-6926, 2019.

Figura 3. O peso de 100 sementes está representado por barras no eixo principal e a produção total no eixo secundário por linhas tracejadas de Mucuna aterrima e Dolichos lablab em diferentes espaçamentos. Bananeiras-PB, UFPB, 2019. Letras maiúsculas comparam as espécies de leguminosas entre si dentro de cada espaçamento. Letras minúsculas comparam os espaçamentos entre si dentro de cada leguminosa.

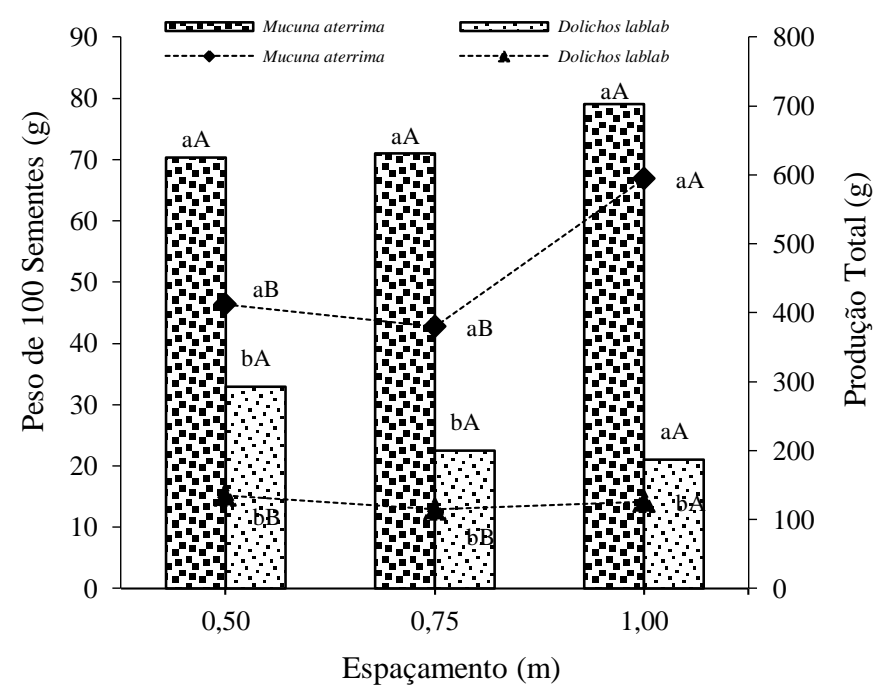

A Mucuna aterrima foi a Fabaceae que apresentou maior peso de vagem com sementes $(3,50 \mathrm{~g})$ em relação ao Dolichos lablab (1,30 g) apresentado na Figura 1. O peso de vagem com semente foi inferior a $8,17 \mathrm{~g}$ verificado por Oliveira et al. (2012), para característica física e morfologia de vagem e semente de feijão bravo. Os menores pesos de vagem com semente observados no presente estudo têm como causa, em parte, o peso da semente de cada espécie, o que pode ser observado através dos resultados obtidos com o peso de semente, sendo que as sementes de $M$. aterrima são mais pesadas do que as de D. lablab, justificando assim, os valores divergentes encontrados nestas condições de estudo.

De acordo com os resultados obtidos, observamos que o peso médio de vagem sem sementes da $M$. aterrima $(1,29 \mathrm{~g})$ foram superiores ao de D. lablab $(0,41 \mathrm{~g})$ (Figura 1). Os resultados obtidos foram inferiores ao encontrado por Oliveira et al. (2012) avaliando as características morfológicas de vagem e sementes, com peso de vagem sem semente de 2,95 g para feijão bravo. Esta diferenciação dos valores pode estar relacionada à expressão das características agronômicas de cada espécie às condições ambientais de cultivo.

O número de sementes obtido para a M. aterrima foi maior do que aquele obtido para o D. lablab (Figura 2). O número de semente por vagem é a característica mais importante a ser avaliada, tendo em vista a semente ser uma forma de propagação das espécies e de importância econômica e comercial (LINHARES et al., 2014).

$\mathrm{O}$ peso de semente apresentou diferença estatística entre a M. aterrima e D. lablab (Figura 2). O melhor resultado foi obtido para a $M$. aterrima. Esse resultado, pode ser justificado pelo fato desta espécie ser mais competitiva e expressar melhor seu potencial de crescimento vegetativo e expressar diretamente no peso da semente em relação ao D. lablab.

O peso de 100 sementes foi influenciado pelos espaçamentos adotados (Figura 1C). A M. aterrima (73,48 g) apresentou o maior valor de peso de 100 sementes em relação ao D. lablab (25,51 g). Santos et al. (2002) verificaram o peso de 100 sementes, que variaram de 32,6 a 79,5 g em oito variedades de fava oriundas do Estado da Paraíba. No entanto, os maiores pesos de vagem com semente e peso de semente foi observado para $M$. aterrima, provavelmente pelo fato de produzir maior número de vagem por área.

O peso de vagem com semente, peso de vagem sem sementes, peso da semente, número de semente por vagem e peso de 100 sementes não foram afetados pelos espaçamentos para ambas espécies, não havendo diferença estatística entre si (Figura 1, 2 e 3). Os espaçamentos das plantas predispõem a mesma exploração ao solo, contribuindo assim para eficiência nas características avaliadas em detrimento ao espaçamento utilizado. $\mathrm{O}$ arranjo populacional e o desempenho da $M$. aterrima e $D$. lab têm evidenciado a importância de estabelecer a densidade de plantio para almejar maior produção de massa seca e sementes de qualidade.

Com relação aos espaçamentos, observou que o espaçamento 1,0 x 0,5 m promoveu a maior produção total da M. aterrima (594,46 g) em relação aos demais espaçamentos, diferindo estatisticamente (Figura 3). Estes resultados estão de acordo com os obtidos por Monteiro et al. (2018) ao avaliarem a morfologia do feijão de porco em diferente espaçamento, quando obtiveram maior produtividade do feijão de porco no espaçamento 1,0 x 0,5 m. Possivelmente a menor quantidade de plantas cultivadas contribuiu para o progresso genético e produtivo. Por isso, pode-se aconselhar a produção dessas leguminosas na região na qual foi conduzido o estudo. 
MONTEIRO, S. S. et al. Produção de leguminosas em função do espaçamento no Brejo Paraibano. In: II Congresso Paraibano de Agroecologia \& IV Exposição Tecnológica, 2019. Anais... Caderno Verde de Agroecologia e Desenvolvimento Sustentável, Pombal, v. 9, n.7, e-6926, 2019.

\section{CONCLUSÕES}

A Mucuna aterrima apresentou melhor desempenho em relação ao Dolichos lablab quanto as variáveis morfológicas. O espaçamento 1,0 x $0,5 \mathrm{~m}$ foi o mais eficiente, promovendo maior produtividade da $M$. aterrima e $D$. lablab, sendo o espaçamento indicado para as condições do Brejo Paraibano.

\section{REFERÊNCIAS}

ARAÚJO, S. L.; MORAIS, R. C.; MORAIS, R.; NUNES, F. R.; COSTA, C.; SANTOS, M. S. Guardiões e guardiãs da agrobiodiversidade nas regiões do Cariri, Curimataú e Seridó Paraibano. Cadernos de Agroecologia, Porto Alegre-RS, v. 8, n. 2, p. 1-5, 2013.

CORRÊA, M. L. P.; TÁVORA, F. J. A. F.; E PITOMBEIRA, J. B. Comportamento de cultivares de mamona em sistemas de cultivo isolados e consorciados com caupi e sorgo granífero. Revista Ciências Agronômica, Fortaleza-CE, v. 37, n. 2, p. 200-207, 2006.

GOMES, T. C.; KARAM, D. Dinâmica populacional de plantas daninhas em áreas com sorgo sacarino e granífero com diferentes espaçamentos e densidades de semeadura. Revista Brasileira de Milho e Sorgo, Sete Lagoas-MG, v. 17, n. 3, p. 390-399, 2018.

LINHARES, P. C. F.; OLIVEIRA, J. D.; PEREIRA, M. F. S.; FERNANDES, J. P. P.; DANTAS, R. P. Espaçamento para a cultura do coentro adubado com palha de carnaúba nas condições de Mossoró-RN. Revista Verde, Pombal-PB, v. 9, n. 3, p. 01- 06, 2014.

LONDRES, F. As sementes da paixão e as políticas de distribuição de sementes na Paraíba. Rio de Janeiro, AS-PTA, 2014. 83 p.

MARES GUIA, A. P. O.; ARAUJO, E. S.; GUERRA, J. G. M.; ESPINDOLA, J. A. A. Avaliação de três espécies de leguminosas quanto ao potencial de produção de biomassa em um sistema de produção familiar no município de Matias Barbosa-MG. Cadernos de Agroecologia, Brasília-DF, v. 13, n. 1, p. 1-5, 2018.

MONTEIRO, S. S.; SANTOS, D. S.; JESUS, J. C.; VASCONCELlOS, A.; LIMA, J. F.; MARINI, F. S. Produção de Canavalia ensiforme em diferentes espaçamentos no estado da Paraíba. Cadernos de Agroecologia, Brasília-DF, v. 13, n. 1, p. 1-7, 2018.

OLIVEIRA, M. E. S.; SILVA, É. R.; SOUSA, E. B.; FARIAS, J. C.; CARVALHO, F. W. A.; ALVES WANDERLEY, P. A. Características físicas e morfológicas de vagens e sementes de feijão-bravo. Anais: VII CONNEPI - Congresso Norte Nordeste de Pesquisa e Inovação, Palma-TO, p. 1-8, 2012.

SANTOS, D.; CORLETT, F. M. F.; MENDES, J. E. M. F.; WANDERLEY JÚNIOR, J. S. A. Produtividade e morfologia de vagens e sementes de variedades de fava no Estado da Paraíba. Pesquisa Agropecuária Brasileira, Brasília-DF, v. 37, n. 10, p. 1407-1412, 2002.

SANTOS, C. M.; GONÇALVES, E. R.; ENDRES, L.; GOMES, T. C. A; JADOSKI, C. J.; NASCIMENTO, L. A.; SANTOS, E. D. Atividade fotossintética em alface (Lactuca sativa L.) submetidas a diferentes compostagens de resíduos agroindustriais. Pesquisa Aplicada e Agrotecnologia, Guarapuava-PR, v. 3, n. 3, p. 95-102, 2010.

SANTOS, A. S.; SILVA, R. L.; AZEVEDO, A. L.; OLIVEIRA, A. S.; SILVA, A. E.; SILVA, C. A. Riqueza florística de Fabaceae em diversos ecossistemas do município de Lábrea, estado do Amazonas, Brasil. Cadernos de Agroecologia, Brasília-DF, v. 13, n. 1, p. 1-7, 2018.

SILVA, A. G. B. GUERRA, J. G. M.; GONÇALVES JUNIOR, M.; COSTA, J. R.; ESPÍNDOLA, J. A. A.; ARAÚJO, E. S. Desempenho agronômico de mucuna verde em diferentes arranjos espaciais. Pesquisa Agropecuária Brasileira, Brasília-DF, v. 46, n. 6, p. 603-608, 2011.

SILVA, M. H. B.; LOPES, K. P. Importância da semente na agricultura familiar no Nordeste Brasileiro. In: Congresso Internacional da Diversidade do Semiárido, 2016, Campina Grande-PB. Anais: I CONIDIS. Campina Grande-PB: Realize Eventos e Editora, v. 1, p. 1-10, 2016.

SOUZA, L. A. G. Leguminosas para adubação verde na terra firme e na várzea da Amazônia central. Um estudo em pequenas propriedades rurais em Manacapuru. INPA/CPCA: Coordenação de Pesquisa em Ciências e Agronômicas, v. 1, n. 40, p. 08-09, 2012. 
MONTEIRO, S. S. et al. Produção de leguminosas em função do espaçamento no Brejo Paraibano. In: II Congresso Paraibano de Agroecologia \& IV Exposição Tecnológica, 2019. Anais... Caderno Verde de Agroecologia e Desenvolvimento Sustentável, Pombal, v. 9, n.7, e-6926, 2019.

SOUZA, F. M.; LIMA, E. C. S.; ALMEIDA, J. F.; MEDEIROS, M. D.; SANTOS, A. S. Avaliação do crescimento inicial de lablab e crotalária no Sertão Paraibano. In: Congresso Internacional da Diversidade do Semiárido, 2016, Campina Grande-PB. Anais: I CONIDIS. Campina Grande-PB: Realize Eventos e Editora, v. 1, p. 1-5, 2016.

WUTKE, E. B.; AMBROSANO, E. J.; RAZERA, L. F.; MEDINA, P. F.; CARVALHO, L. H.; KIKUTI, H. Bancos comunitários de sementes e adubos verdes: informações técnicas. Brasília: MAPA, 52p., 2007.

\section{AGRADECIMENTOS}

Apoio financeiro: Fundação de Apoio à Pesquisa do Estado da Paraíba - FAPESQ. 